\title{
Supporting the next generation of non-communicable disease research leaders in Africa - experience of the GSK Africa NCD Open Lab
}

\author{
Juliet Addo ${ }^{1}$, Mike Strange ${ }^{1}$, Lindsay Kendall ${ }^{1}$, Annie Stylianou${ }^{1}$, Sally Gatsi ${ }^{2}$, Phyllis Guta ${ }^{1}$, Rhona Scott $^{1}$, Agbor Ako \\ ${ }^{1}$ Africa Non-communicable Disease Open Lab, GlaxoSmithKline, Stevenage, United Kingdom, ${ }^{2}$ GlaxoSmithKline, Collegeville, Pennsylvania, United \\ States \\ Keywords: glaxosmithkline, africa, non-communicable diseases
}

https://doi.org/10.29392/001c.12274

\section{Journal of Global Health Reports}

Vol. 4, 2020

\section{Background}

Despite a large and increasing non-communicable diseases (NCD) burden in Africa, research to inform NCD risk factors, management and outcomes in African populations is limited.

\begin{abstract}
Methods
The GlaxoSmithKline (GSK) Africa NCD Open Lab targeted outstanding early career African scientists, providing funding and scientific support for projects designed and led by African investigators to increase NCD understanding. Applicants were eligible if based in research institutions/universities in Cameroon, Côte D'Ivoire, Ethiopia, Ghana, The Gambia, Kenya, Malawi, Nigeria, Senegal, Tanzania and Uganda. Proposals in scope addressed cardiovascular disease, oncology, chronic respiratory disease, chronic kidney disease and diabetes, and could examine relationships between these NCDs and infectious diseases, including across the life-course. Ten awards offering up to $£ 100,000$ (US\$128,500) for two years' funding were available to cover research project costs. Additionally, GSK offered in-kind scientific support and mentoring throughout the award duration.
\end{abstract}

\section{Results}

From 330 unique proposals submitted, 225 met the eligibility criteria covering cardiovascular disease (25.8\%), metabolic disorders (23.1\%), oncology (17.8\%), respiratory disease (8.9\%), chronic kidney disease (7.1\%), and 'other' (17.3\%). The highest number of eligible applications were by researchers from Nigeria (28.4\%), Kenya (15.1\%), and Uganda (14.2\%). Following a multi-stage review process by GSK scientists and an independent Scientific Advisory Board of predominantly African scientists, nine proposals were recommended for funding and collaborative support; three cardiovascular, two respiratory, two chronic kidney disease, and two diabetes. The most common training needs identified by applicants were biostatistics, grants management, clinical trial design, and writing for publication.

\section{Conclusions}

By supporting open innovation research, the GSK Africa NCD Open Lab identified a substantial number of African early career researchers enthusiastic to engage in projects relevant to NCDs. In addition to funding, capacity building efforts are critical to ensure sustainable NCD research and a thriving African research community.

A rapid rise in the incidence of non-communicable diseases (NCDs) in Africa is projected to result in a $27 \%$ increase in deaths, or an additional 28 million deaths by $2030 .^{1,2}$ As elsewhere, NCDs threaten public health and social development in Africa. ${ }^{2,3}$ Additionally, the double burden of NCDs and infectious diseases presents complex challenges to African healthcare systems. ${ }^{4-6}$

A strong and innovative regional research community is required to develop effective strategies to understand and manage NCDs and curb the trend for their increased impact in Africa. There is a clear need for more investigator-led studies regarding NCDs in Africa, which seek to develop strategies specific to the local situation aimed at improving the health of African communities. ${ }^{4,6,7}$ However, clinical research in sub-Saharan Africa is mainly funded by industry, governments or foundations/philanthropies, is usually dominated by grants from foreign funders, ${ }^{8}$ and often focused on infectious diseases, such as HIV and tuberculosis. ${ }^{9}$ 
Such studies are often undertaken in collaboration with American and European institutions, and the inclusion of African perspectives is not always apparent. For example, African scientists' roles are often confined to data collection rather than research design. ${ }^{10}$ Sustainability and expansion of research capacity once a particular programme has been completed is also a key challenge, even in well-established research institutions. ${ }^{11}$

The GlaxoSmithKline (GSK) Africa NCD Open Lab was established in 2014 to support high quality epidemiological, genetic, mechanistic and interventional research projects to increase understanding of NCDs, designed and led by investigators based in sub-Saharan Africa. ${ }^{12}$ Supported by an independent Scientific Advisory Board (SAB), predominantly consisting of African scientists, the Africa NCD Open Lab launched its first call for proposals in 2014 across eight African countries, with $£ 4$ million (US\$5.1 million) made available. ${ }^{13}$ Five high quality research proposals were funded, with principal investigators from Nigeria, Uganda and Malawi. ${ }^{13}$ Already, some of these projects have been completed and published in leading journals, ${ }^{14-17}$ with more papers currently under consideration. In 2015, a second call for proposals was launched via a $£ 5$ million (US\$6.4 million) collaboration between GSK and the Medical Research Councils of the UK and South Africa. ${ }^{18}$ Using a similar model, the call provided an opportunity to support researchers from South African institutions conducting research projects in NCDs.

Following these calls for proposals, a critical gap in research support was identified regarding early career researchers in Africa. Through multi-stakeholder engagements, including discussions with the SAB, the post-doctoral period was identified as an extremely challenging phase. ${ }^{19}$ The transition to becoming a research scientist can be impaired, not just by the limited funding opportunities, but more importantly by local institutional factors, such as a lack of post-doctoral positions, high teaching demands and limited mentoring opportunities. ${ }^{19}$ It is often difficult for these early career researchers to compete successfully for research funding with senior colleagues with more impressive track records. Consequently, many researchers may leave the continent to develop their careers in Europe and North America. As Africa is facing a rising burden of NCDs, which will likely worsen over the next decades, this drain on human resources needs to be better understood, and African research networks need to be primed to retain researchers.

The aim of the 2016 Open Lab funding round (third call for proposals) was to focus on African scientists at an early stage of their career. The objective was to support research projects from a cadre of next-generation African researchers who will direct a significant proportion of their career towards NCD research within the continent. Similar to previous calls, in addition to research funding, independent technical (clinical, scientific and statistical) support by GSK scientists and academic partners was offered, both in proposal development and project delivery.

This paper outlines the processes involved in launching and facilitating the call for proposals targeting early career researchers. The identified gaps and opportunities for supporting emerging research leaders in sub-Saharan Africa are also discussed.

\section{Box 1. Paper context}

Despite a growing health burden, research to improve the understanding of the aetiology of non-communicable diseases (NCDs) in African populations remains limited. The GSK Africa NCD Open Lab sought proposals from early career African researchers that addressed locally relevant research questions necessary to inform NCD prevention and treatment strategies. Funding and in-kind technical support was offered, with nine projects selected. The process demonstrated a workable industry-academic partnership model allowing African researchers to define their own research questions and develop their research potential.

\section{METHODS}

\section{CALL FOR PROPOSALS}

The call for research proposals was advertised on www.gsk.com and through various media channels in the included countries, with significant input from GSK local country medical directors. It targeted outstanding African scientists in the early stages of their research and academic careers based in research institutions or universities in the following countries: Cameroon, Côte d'Ivoire, Ethiopia, Ghana, The Gambia, Kenya, Malawi, Nigeria, Senegal, Tanzania and Uganda. These countries were chosen based on where GSK could provide country-level support via a regional or local operating company office. Funding was available for rigorous, high-quality epidemiological, genetic, mechanistic and interventional primary research in at least one of the following priority NCD areas: cardiovascular disease, oncology, chronic respiratory disease, chronic kidney disease and diabetes. Proposals could additionally examine the interplay between these NCDs and infectious diseases and could consider NCDs longitudinally across the life-course. Strategically, the funding aimed to enable early career researchers to lead competitive independent research programmes. Additionally, the projects were expected to generate significant data, further strengthening funding proposals potentially leading to more sizeable, grant funding from other organisations in the longer term.

\section{TERMS OF THE AWARD}

Ten awards of up to $£ 100,000$ (US\$128,500) each for two years of funding were made available. The award covered the cost of an appropriate research project including equipment, field work and data collection, consumables, and research assistance and training activities relevant to achieving the aims of the project (including short courses and training visits to relevant research institutions and conferences). In addition to financial support, GSK offered in-kind technical support, training and mentoring throughout the duration of the award without pre-defined limits. The lev- 
el of interaction was determined during the application and review process and was dependent on the individual needs of the investigator and the project. In collaboration with the British Medical Journal (BMJ), GSK also made available the BMJ's 'Research to Publication eLearning programme' for 12 months, for up to 50 researchers from 30 African institutions (including all those with applicants shortlisted to submit full proposals). The modules focussed on healthcare research, guiding learners through the entire research process from designing a study to seeing it published in an international journal (http://rtop.bmj.com/).

\section{ELIGIBILITY CRITERIA}

To be eligible, applicants must: 1 ) be the principal investigator and an early career researcher, defined as a basic biomedical scientist, clinically qualified investigator or public health researcher, who had not previously competed successfully as principal investigator for a major research grant, and was no more than ten years from their highest degree of study (career breaks and time out of academic research were taken into consideration); 2) be currently employed by an eligible academic, health or research institution in a country specified in the call for proposals (Cameroon, Côte d'Ivoire, Ethiopia, Ghana, The Gambia, Kenya, Malawi, Nigeria, Senegal, Tanzania and Uganda) for the duration of the project; 3 ) be a national of one of those countries; 4) hold a $\mathrm{PhD}$ or equivalent higher degree (e.g. $\mathrm{DrPH})$ in a health-related discipline, or if pursuing a clinical academic career without a $\mathrm{PhD}$, have completed their specialist training in a relevant aspect of medicine and have demonstrated relevant research experience (e.g. MSc with a research component); 5) not currently hold positions above the UK equivalent of lecturer; 6) demonstrate a track record and ongoing commitment to health-related research and the skills and experience required to carry out the proposed work. Additionally, evidence of research output, including publications in peer reviewed journals and/or presentations at scientific conferences was required.

Institutions were eligible if: 1) the head of department of the host institution in which the award would be based confirmed support for the application and that, if funded, the research and training would be supported with appropriate space and facilities and administered in the name of the institution; 2) an appropriate local supervisor/mentor with relevant research experience and output and evidence of previous funding employed in the institution of the applicant confirmed their support of the applicant and the proposed project. However, the supervisor did not have to be working in the field of NCDs to be eligible.

\section{RESULTS}

\section{PROGRESSION AND SELECTION OF APPLICATIONS}

Of the 330 unique proposals submitted (after removing 110 submitted in error and duplicates), 225 were complete and met the eligibility criteria and progressed into the review process (Figure 1). The proposals covered a wide range of NCDs including cardiovascular disease (25.8\%), diabetes and metabolic disorders (23.1\%), oncology (17.8\%), chronic respiratory disease $(8.9 \%)$, chronic kidney disease $(7.1 \%)$ and 'other' (17.3\%), such as sickle cell disease, health systems research and oral health (Figure 2). Each proposal was reviewed and scored independently by at least two GSK scientists and one statistician prior to review by the African NCD Open Lab SAB members and discussion at a face-toface meeting.

Following the first SAB meeting, 16 shortlisted applicants were invited to submit full proposals providing more details on the research project. At this stage, GSK offered support to the applicants, providing scientific and statistical input if this was requested. The aim was to ensure that the proposals were scientifically and ethically robust. Full proposals were reviewed and scored by the SAB. One of the 16 shortlisted applicants pulled out of the process leaving 15 proposals for discussion at the final board meeting. Ten highest scoring proposals were recommended for funding based on their scientific quality, potential for impact, and strategic importance to Africa. To ensure that funded studies had a high probability of success, due diligence site visits were conducted at all the institutions, during which GSK scientists assessed the suitability of the local research environment and, where appropriate, shared best research practice. One of the studies (a preclinical study) was not progressed to receive funding following the due diligence site visit as the institution lacked a program for animal care and use. The final list of nine funded projects progressed to receive funding is outlined in Table 1 . The projects covered different NCDs as well as their associations with infectious diseases and included diabetes (two), chronic obstructive pulmonary disease (one), chronic kidney disease in a birth cohort of children (one), cardiovascular diseases in pregnancy (two), cardiovascular disease in HIV patients (one), chronic renal disease in HIV patients (one) and chronic obstructive pulmonary disease in HIV patients (one).

\section{CHARACTERISTICS OF APPLICANTS}

Characteristics of the applicants are shown in Figure 3. The highest number of eligible applications were by researchers from Nigeria (28.4\%), Kenya (15.1\%) and Uganda (14.2\%). One third of eligible applications were from women and three of the nine finally accepted proposals were from women. The majority of applicants were at lecturer level or below, as specified in the eligibility criteria. There were a few applications from researchers who were at higher professional grades, but their research track records indicated they were early career researchers and hence eligible to apply. Of the 225 eligible applicants, 83 (36.9\%) had completed $\mathrm{PhD}$ and 5 out of the 9 finally funded applicants (55.6\%) had completed a PhD.

\section{TRAINING NEEDS}

To help identify and address key training gaps, participants were asked to indicate up to three areas they considered as training gaps from a list of 10 provided. Biostatistics, grants management, clinical trial design and writing for publication were the training areas that were chosen most frequently (Figure 4). Areas considered among the 'others' included bioinformatics, proteomics and metabolomics. 


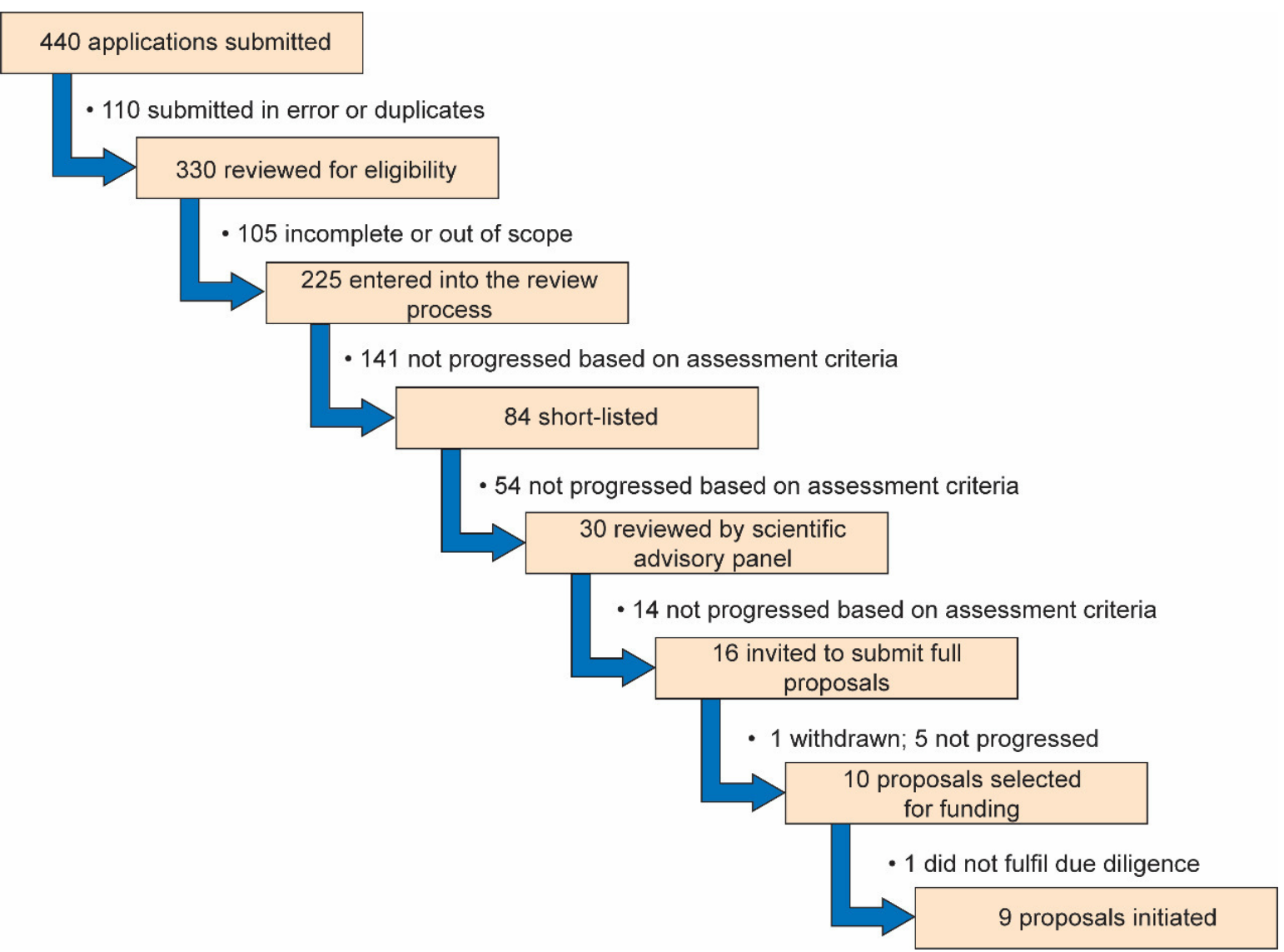

Figure 1. Flow of research proposal applications through the review process.

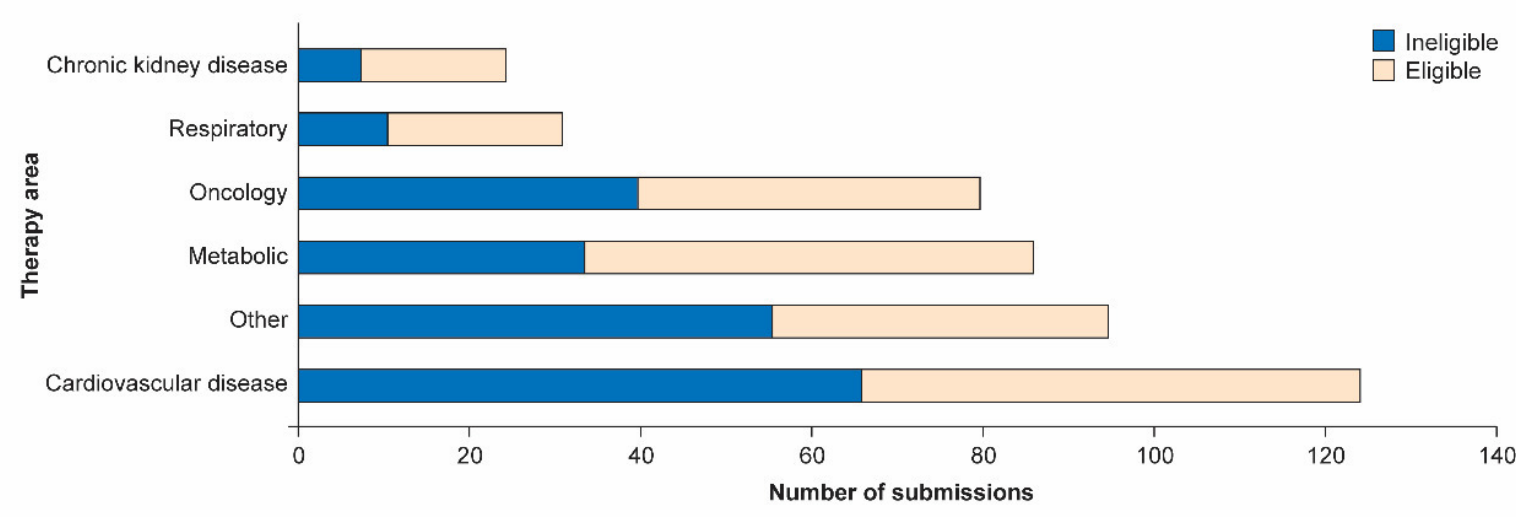

Figure 2. Distribution of non-communicable disease areas included in the research proposal applications.

\section{DISCUSSION}

This call for proposals in NCD research from early career researchers yielded an excellent response from applicants based in different countries in sub-Saharan Africa and from academic and research institutions that ranged from wellestablished research programmes and collaborations to those with fewer current research programmes. However, applications from more established institutions and from applicants whose mentors had an extensive research track record, including international collaborations, were often of a higher quality and more likely to be successful. Future opportunities should consider promoting collaborative activities between African institutions with more limited research capacity and those with more experience and capacity. In particular, there were relatively fewer proposals from the two eligible Francophone countries, indicating that additional work may be needed to understand the underlying reason for this discrepancy. Also, further work is needed to 

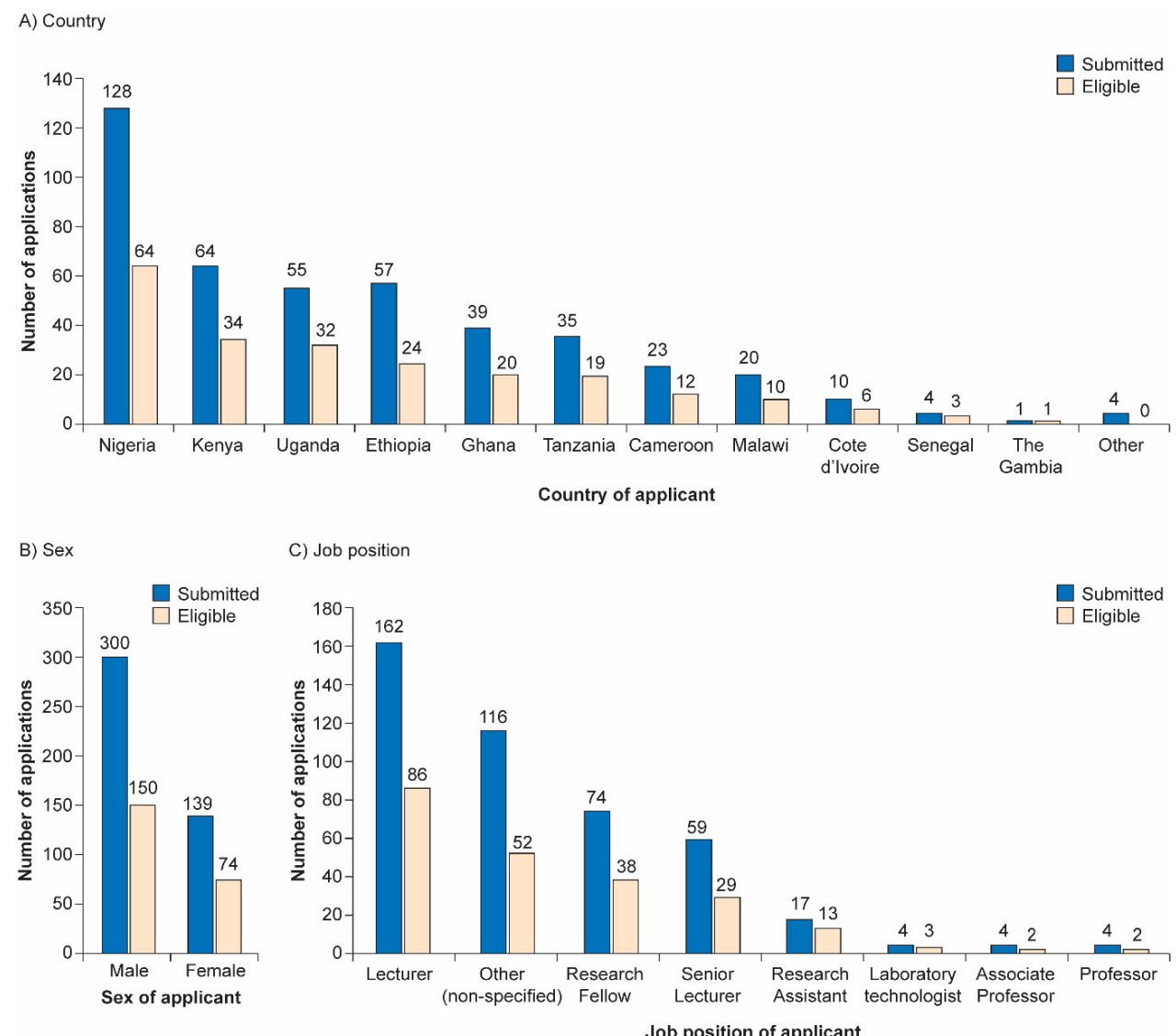

Figure 3. Characteristics of applicants in terms of their (A) country, (B) sex (one applicant declined to provide this information) and (C) job position.

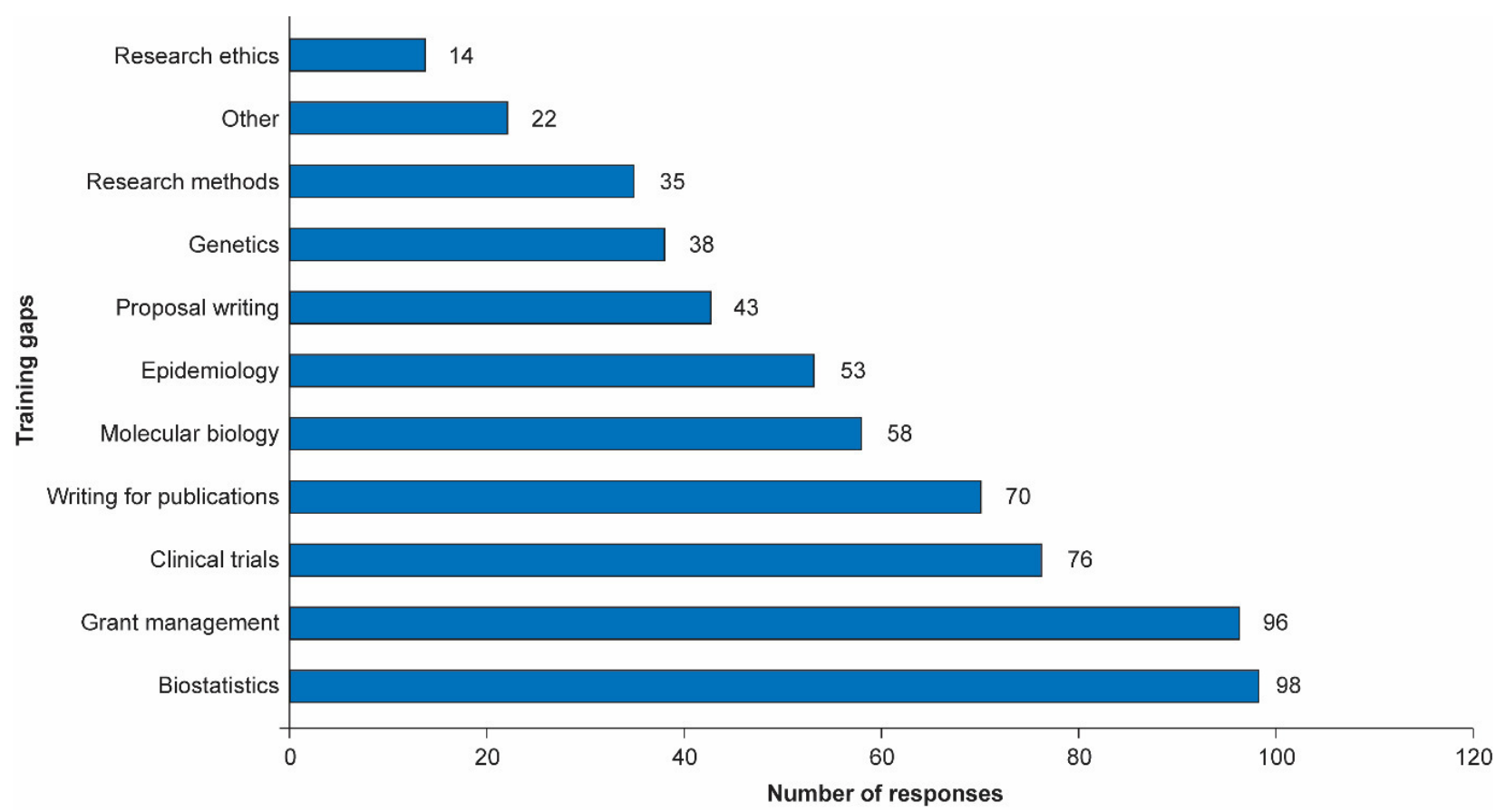

Figure 4. Training gaps identified by applicants (applicants were asked to provide their top three training gaps).

ensure increased participation from women researchers. Industry funding for medical research in Africa and else- where is often directed to clinical trials of new drugs. It is, therefore, important to ensure increased research capabili- 
ties and infrastructure to undertake drug trials in Africa. A unique feature of the NCD Africa Open Lab call for proposals was that it was not targeted at clinical trials of medicines or investigational medicinal products of any kind. Importantly, it sought to encourage and support researchers with an interest in NCDs at a critical time in their careers. Consequently, a significant number of submitted proposals aimed to explore unique and innovative research questions and hypotheses pertinent to the health needs of Africa which would not normally have attracted funding.
Mentoring and coaching have been identified as valuable support mechanisms for academics transitioning from teaching and data gathering to developing their own research programmes..$^{21-24}$ Key to the Africa NCD Open Lab model is the requirement for an institutional mentor to be appointed and the opportunity to work with GSK scientists and researchers. This support was offered on an 'as needed' basis and covered a diversity of disciplines. 


\begin{tabular}{|c|c|c|}
\hline Country & Study title [ref] & Potential outcomes \\
\hline Tanzania & $\begin{array}{l}\text { Cardiovascular diseases (CVD) in pregnancy in Tanzania: burden, characterisation and their } \\
\text { prognostic significance at delivery }\end{array}$ & $\begin{array}{l}\text { - Inform prevention and treatment strategies for the care of pregnant women with CVD. } \\
\text { - Update guidelines and policies with regard to the risks of CVD in pregnancy. } \\
\text { - Provide objective data to support counselling of women about pregnancy safety. } \\
\text { - Contribute to efforts to reduce morbidity and mortality associated with pregnancy in Tanzania. }\end{array}$ \\
\hline Tanzania & $\begin{array}{l}\text { Prospective exploration of the effect of adiposity and associated microbial factors on healing } \\
\text { and progression of diabetic foot ulcers (DFUs) in Tanzania } 20\end{array}$ & $\begin{array}{l}\text { - Update and improve management guidelines for DFU care by providing information on the physiological and metabolic determinants of } \\
\text { DFUs. } \\
\text { - Guide and support the treatment of DFUs, which may ultimately reduce diabetes-related morbidity and mortality. }\end{array}$ \\
\hline Kenya & Chronic inflammation and early risk of atherosclerosis among HIV-infected adults in Kenya & $\begin{array}{l}\text { - Increase understanding of biological mechanisms linking chronic viral infection, inflammation and CVD, which is of relevance to both HIV } \\
\text { infected and uninfected populations. } \\
\text { - Provide biomarkers/mechanisms to identify HIV patients at increased risk of developing CVD, as well as support earlier implementation of } \\
\text { preventive and therapeutic measures. } \\
\text { - Reduce the incidence of associated complications in HIV-infected adults. } \\
\text { - Support the development of CVD risk scores that incorporate inflammatory markers. }\end{array}$ \\
\hline Uganda & $\begin{array}{l}\text { Future maternal cardiovascular health after pre-eclampsia in an indigenous African } \\
\text { population }\end{array}$ & $\begin{array}{l}\text { - Generate new knowledge on the pathophysiology of pre-eclampsia. } \\
\text { - Characterise an important cohort that can be followed up in the longer term to examine definitive cardiac disease outcomes. } \\
\text { - Inform policy and clinical guidelines that may improve the management of women with pre-eclampsia which could ultimately lead to a } \\
\text { reduction in perinatal and maternal morbidity and mortality. } \\
\text { - Identify women most at risk of later CVD after pre-eclampsia who would benefit from prolonged follow up and early therapeutic intervention } \\
\text { and development of policies to prioritise scarce resources for these women. } \\
\text { - Develop a platform for more extensive future studies on the genomics of cardio-metabolic disorders. }\end{array}$ \\
\hline Uganda & $\begin{array}{l}\text { Frequency and predictors of exacerbations within a chronic obstructive pulmonary diseases } \\
\text { (COPD) population in Uganda }\end{array}$ & $\begin{array}{l}\text { - Identify those at risk of COPD exacerbation and provide targeted education on avoidance of triggers and self-management of attacks, as well } \\
\text { as possible vaccination and provision of other treatments to reduce patients' future risk. } \\
\text { - Reduce the higher mortality caused by COPD exacerbations in Uganda and other low-to-middle income countries, in particular those in } \\
\text { Africa. } \\
\text { - Fill the knowledge gap related to the frequency and factors that affect increased exacerbations within this population related to COPD. }\end{array}$ \\
\hline Uganda & $\begin{array}{l}\text { Investigating the association between altered lung microbiome and HIV-associated COPD in a } \\
\text { Ugandan cohort }\end{array}$ & $\begin{array}{l}\text { - Improve the understanding of COPD pathogenesis and short-term natural history in Uganda and in the setting of HIV to help determine } \\
\text { screening strategies and treatments. } \\
\text { - Fill an important gap in the scientific literature which may lead to further studies informing the development of new therapies for COPD in } \\
\text { Africa and globally. } \\
\text { - Provide initial data for specific precision medicine strategies for treating COPD and other respiratory diseases in Africa, particularly among } \\
\text { HIV-infected subject cohorts. }\end{array}$ \\
\hline Ethiopia & $\begin{array}{l}\text { The association of kidney function and kidney size with low birth weight and stunting in } \\
\text { Ethiopian children }\end{array}$ & $\begin{array}{l}\text { - Provide insights on the factors associated with chronic kidney disease (CKD) in Ethiopia, especially those associated with early life nutrition } \\
\text { and sociodemographic factors in childhood. } \\
\text { - Early identification of high-risk patients to inform prevention strategies and improve the outcome of CKD. } \\
\text { - Provide policy makers and healthcare planners with the necessary data to inform local policy on improvement of maternal and child health } \\
\text { and guide nutritional interventions to prevent low birth weight and stunting in Ethiopia. }\end{array}$ \\
\hline Nigeria & $\begin{array}{l}\text { Prevalence and pharmacogenomics of tenofovir nephrotoxicity in HIV-infected adults in } \\
\text { south-western Nigeria }\end{array}$ & $\begin{array}{l}\text { - Improve the early detection of renal dysfunction in HIV patients. } \\
\text { - Implement a reliable strategy to detect and avoid tenofovir-induced kidney tubular dysfunction (KTD). } \\
\text { - Improve understanding of the pathogenesis of complex pharmacogenomic interactions to develop novel tools to monitor kidney health. } \\
\text { - Inform the development of clinical management programs to reduce the burden of KTD in Nigeria and in other populations. }\end{array}$ \\
\hline Malawi & $\begin{array}{l}\text { Biochemical characterisation of people with type } 2 \text { diabetes attending the diabetes clinic at } \\
\text { Queen Elizabeth Central hospital, in Blantyre, Malawi }\end{array}$ & $\begin{array}{l}\text { - Increase the understanding of the varied phenotypes of type } 2 \text { diabetes in Malawi. } \\
\text { - Inform the development of clinical guidelines and protocols for accurately classifying and managing type } 2 \text { diabetes in Malawi and in sub- } \\
\text { Saharan Africa. } \\
\text { - Guide prevention strategies and policies aimed at addressing the increasing burden of diabetes in Africa. }\end{array}$ \\
\hline
\end{tabular}


The most commonly sought help was in biostatistics, grants management, clinical trial design and writing for publication. These are areas in which GSK has significant expertise and access was provided to existing training programmes. Input from the GSK statistical group, providing advice on computational biology, study design and statistical analysis methods, was considered highly important and valued by the researchers.

It is notable that the areas identified for training were generally 'companion' skills not directly related to the research. Such skills are not generally included in basic scientific training but rely on additional support from senior colleagues or specific development courses. As this programme demonstrated, some of these skills can be acquired via elearning, and there is an opportunity to widen access to resources that would help researchers to bridge the training gaps that are preventing them from accessing grants and advancing their careers. In collaboration with the BMJ, an educational package offering free access for one year to online modules covering various aspects of research including writing for publications was made available to up to 50 researchers from 30 African institutions (total 1,500 access). Researchers who engaged with these modules found them to be very useful, addressing their learning needs. It will be beneficial for funders to explore further the use of such modules to address knowledge gaps and to expand access to online materials including journals to African researchers in various locations.

Due diligence and governance processes, including a comprehensive site visit, was an important step in the finalisation of funding. Feedback about the visit received from investigators and their research teams was always positive and allowed discussion regarding the possible areas for scientific engagement during the course of the project. The visits also provided the platform to establish trust with the research organisations and together explore realistic and feasible ways to minimise any potential risks that could hinder the timely and successful completion of the project. Our experience suggests that such due diligence site visits are an essential component of any research collaboration.

For example, the only pre-clinical study that was shortlisted was not progressed as the due diligence visit identified shortcomings in the animal welfare policies at the institution relative to internationally recognised standards. The $\mathrm{SAB}$ believed that this reflected a more general lack of infrastructure within African institutions for conducting preclinical studies. Detailed feedback on aspects of the animal care program that required improvement was provided to the investigator and their team. Subsequently, an animal care program for research was established at this institution in line with international guidelines.

\section{CONCLUSIONS}

The gap in academia in sub-Saharan Africa, associated with a 'missing middle' of researchers who either left the region or did not have the opportunity to develop a research programme, requires addressing if biomedical research is going to have an impact on the increasing burden of NCDs. ${ }^{19}$ Bridging the early career gap is critical for researchers to progress in their career and address important research questions. Moreover, research opportunities need to focus on African needs if they are to provide data that improves the health of African populations while generating meaningful and sustainable research careers for a new generation of African scientists and clinicians. ${ }^{19}$ This latest call for proposals from the GSK Africa NCD Open Lab demonstrates that there is a large number of early career African researchers enthusiastic to work in NCDs. As a model for industry, it also shows that collaborations can be established with academia, while providing room for African researchers to define their own research questions and agendas and further develop their research potential.

Acknowledgements: The authors sincerely thank the Scientific Advisory Board for their guidance, support and enthusiasm during the project. Naomi Richardson of Magenta Communications Ltd developed a first draft of this article based on an internal report, provided editing and graphic services and was funded by GlaxoSmithKline. The authors would like to thank all the applicants who took part in the Africa NCD Open Lab call for proposals.

Ethics and consent: Not applicable.

Funding: This project was funded by GlaxoSmithKline.

Authorship contributions: All the authors were involved in the design of the GSK Africa NCD Open Lab call for proposals and collected data related to the project. All the authors critically reviewed the paper and take responsibility for its final contents.

Conflicts and disclosure statement: The authors are employees of GlaxoSmithKline and hold shares in the company.

\section{Correspondence to:}

Dr Juliet Addo

Global Health Catalyst, Global Health R\&D

GSK, Gunnels Wood Road, Stevenage

Hertfordshire, SG1 2NY, United Kingdom

+44 (0) 1438745745

juliet.x.addo@gsk.com 


\section{REFERENCES}

1. World Health Organization. Noncommunicable Diseases. Geneva: WHO; 2017. https://www.who.int/n ews-room/fact-sheets/detail/noncommunicable-disea ses.

2. World Health Organization. Global Action Plan for the Prevention and Control of Noncommunicable Diseases 2013-2020. Geneva: WHO; 2013. https://app s.who.int/iris/bitstream/handle/10665/94384/9789241 506236_eng.pdf.

3. Boutayeb A. The double burden of communicable and non-communicable diseases in developing countries. Trans R Soc Trop Med Hyg. 2006;100(3):191-199. doi:10.1016/j.trstmh.2005.07.02 1

4. Nyirenda MJ. Non-communicable diseases in subSaharan Africa: Understanding the drivers of the epidemic to inform intervention strategies. Int Health. 2016;8(3):157-158. doi:10.1093/inthealth/ihw $\underline{021}$

5. Remais JV, Zeng G, Li G, et al. Convergence of noncommunicable and infectious diseases in low- and middle-income countries. Int J Epidemiol. 2013;42(1):221-227. doi:10.1093/ije/dys135

6. Marais BJ, Lonnroth K, Lawn SD. Tuberculosis comorbidity with communicable and noncommunicable diseases: Integrating health services and control efforts. Lancet Infect Dis. 2013;13(5):436-448. doi:10.1016/S1473-3099(13)7001 $\underline{5-X}$

7. Isaakidis P, Swingler GH, Pienaar E, et al. Relation between burden of disease and randomised evidence in sub-Saharan Africa: Survey of research. BMJ. 2002;324(7339):702. doi:10.1136/bmj.324.7339.702

8. Moses H, Dorsey ER, Matheson DH, et al. Financial anatomy of biomedical research. Jama. 2005;294(11):1333-1342. doi:10.1001/jama.294.11.13 $\underline{33}$

9. London L, Naledi T, Petros S. Health research in the Western Cape province, South Africa: Lessons and challenges. African journal of primary health care \& family medicine. 2014;6(1):E1-7. doi:10.4102/phcfm.v $\underline{6 i 1.698}$

10. Boshoff N. Neo-colonialism and research collaboration in Central Africa. Scientometrics. 2009;81(2):413-434. doi:10.1007/s11192-008-2211-8
11. Mwangoka G, Ogutu B, Msambichaka B, et al. Experience and challenges from clinical trials with malaria vaccines in Africa. Malar J. 2013;12:86. doi:1 $\underline{0.1186 / 1475-2875-12-86}$

12. Hall MD, Dufton AM, Katso RM, et al. Strategic investments in non-communicable diseases (NCD) research in Africa: The GSK Africa NCD Open Lab. Cardiovasc J Afr. 2015;26(2 Suppl 1):S15-17. doi:10.58 30/CVIA-2015-042

13. Gatsi S, Strange M, Dufton A, et al. Driving a greater understanding of non-communicable diseases in Africa through collaborative research: The experience of the GSK Africa NCD Open Lab. J Glob Health Rep. 2018;2:e2018012. doi:10.29392/joghr.2.e $\underline{2018012}$

14. Ojji DB, Poulter N, Damasceno A, et al. Rationale and design of the comparison of 3 combination therapies in lowering blood pressure in black Africans (CREOLE study): $2 \times 3$ factorial randomized singleblind multicenter trial. Am Heart J. 2018;202:5-12. do i:10.1016/j.ahj.2018.03.023

15. Ojji DB, Mayosi B, Francis V, et al. Comparison of dual therapies for lowering blood pressure in black Africans. N Engl J Med. 2019;380(25):2429-2439. do i:10.1056/NEJMoa1901113

16. Leake I. Lowering blood pressure in black African patients. Nat Rev Cardiol. 2019;16(6):323. doi:10.103 8/s41569-019-0193-2

17. Kirenga B, Chakaya J, Yimer G, et al. Phenotypic characteristics and asthma severity in an East African cohort of adults and adolescents with asthma: Findings from the African severe asthma project. $B M$ J Open Respir Res. 2020;7(1). doi:10.1136/bmjresp-201 9-000484

18. GlaxoSmithKline. GSK joins with research councils in UK and South Africa to tackle noncommunicable diseases in Africa Brentford: GSK. 2014. https://www.gsk.com/en-gb/media/press-releas es/gsk-joins-with-research-councils-in-uk-and-sout h-africa-to-tackle-non-communicable-diseases-in-af rica/.

19. The British Academy, The Association of Commonwealth Universities. Foundations for the Future: Supporting the Early Careers of African Researchers London: The British Academy/ Association of Commonwealth Universities.; 2011. htt ps://www.idea-phd.net/images/doc-pdf/Foundation s for the Future.pdf. 
20. Mashili F, Joachim A, Aboud S, et al. Prospective exploration of the effect of adiposity and associated microbial factors on healing and progression of diabetic foot ulcers in Tanzania: Study protocol of a longitudinal cohort study. BMJ Open.

2019;9(12):e031896. doi:10.1136/bmjopen-2019-0318 $\underline{96}$

21. Roets L, van Rensburg EJ, Lubbe J. Faculty’s experience of a formal mentoring programme: The perfect fit. Afr Health Sci. 2019;19(2):2237-2242. do i:10.4314/ahs.v19i2.49

22. Bennett S, Paina L, Ssengooba F, et al. Mentorship in African health research training programs: An exploratory study of Fogarty International Center Programs in Kenya and Uganda. Educ Health (Abingdon). 2013;26(3):183-187. doi:10.4103/1357-62 83.126001
23. Chege MP. Building consensus on identifying research mentoring gaps and finding ways of addressing the gap in a Kenyan college of health sciences. African journal of primary health care \& family medicine. 2019;11(1):e1-e7. doi:10.4102/phcf m.v11i1.1886

24. Chi BH, Belizan JM, Blas MM, et al. Evaluating academic mentorship programs in low- and middleincome country institutions: Proposed framework and metrics. Am J Trop Med Hyg. 2019;100(1_Suppl):36-41. doi:10.4269/ajtmh.18-0561 